\title{
Medial femoral condyle vascularised corticoperiosteal graft: A suitable choice for scaphoid non-union
}

\author{
Samir Kumta, Sudhir Warrier ${ }^{1}$, Leena Jain², Rani Ummal, Manik Menezes ${ }^{3}$, Shrirang Purohit \\ Departments of Plastic and Reconstructive Surgery and ${ }^{1}$ Orthopaedic and Hand Surgery, Lilavati Hospital and Research \\ Centre, ${ }^{2}$ Department of Plastic and Reconstructive Surgery, S. L. Raheja - Fortis Hospital and Research Centre, Mumbai, \\ Maharashtra, India, ${ }^{3}$ Department of Plastic and Reconstructive Surgery, International Modern Hospital, Dubai, UAE
}

Address for correspondence: Dr. Leena Jain, No. 301, C Wing, Dheeraj Presidency, M. G. Road, Kandivali West, Mumbai - 400067, Maharashtra, India. E-mail: link.jain@gmail.com

\section{ABSTRACT}

Introduction: Scaphoid fractures are not very common and frequently remain undiagnosed, presenting in non-union and persistent wrist pain. Options for scaphoid fracture treatment have been described over several decades, however, none with an optimal solution to achieve union along with good hand function. We describe here, the use of vascularised corticoperiosteal bone grafts from the medial femoral condyle (MFC) as a solution for the difficult problem of scaphoid fracture non-union. Materials and Methods: This series has 11 patients with non-union following a scaphoid fracture treated over 18 months ranging from January 2014 to January 2016 using a vascularised corticoperiosteal graft from the MFC. Bone graft fixation was done using K-wires and anastomosis was done with the radial vessels. Results: There were no cases of flap loss. Time of union was an average 3 months. All patients had a full range of movements. Discussion: MFC is an ideal site for harvesting vascularised corticoperiosteal grafts providing a large surface of tissue supplied by a rich periosteal plexus from the descending genicular artery. No significant donor site morbidities have been reported in any series in the past. The well-defined anatomy helps in a rather simple dissection. Corticoperiosteal grafts have a high osteogenic potential and hence, this vascularised graft seems ideal for small bone non-unions. Conclusion: Thin, pliable and highly vascularised corticocancellous grafts can be obtained from the MFC as an optimal treatment option for scaphoid non-unions.

\section{KEY WORDS}

Corticoperiosteal grafts; medial femoral condyle; non-union

\section{INTRODUCTION}

rom the use of vascularised bone grafts for long

$\checkmark$ bone defects, we have come a long way in all aspects of bone graft harvesting sites, bone graft

\begin{tabular}{|l|l|}
\hline \multicolumn{2}{|c|}{ Access this article online } \\
\hline Quick Response Code: & Website: \\
\hline & www.ijps.org \\
\cline { 2 - 2 } & Dol: \\
\hline
\end{tabular}

designing methods and composite soft tissue and bony reconstructions. However, the problems associated with healing and union of small bones in the presence of

This is an open access article distributed under the terms of the Creative Commons Attribution-NonCommercial-ShareAlike 3.0 License, which allows others to remix, tweak, and build upon the work non-commercially, as long as the author is credited and the new creations are licensed under the identical terms.

For reprints contact: reprints@medknow.com

How to cite this article: Kumta $S$, Warrier $S$, Jain $L$, Ummal R, Menezes M, Purohit S. Medial femoral condyle a scularised corticoperiosteal graft: A suitable choice for scaphoid non-union. Indian J Plast Surg 2017;50:138-47. 
avascularity are yet not small in terms of the magnitude of time required for healing and the number of procedures that are often required, many without encouraging success rates.

These include most commonly the carpus and the interphalangeal joints where non-union is a serious and morbid condition affecting activities of daily living and resulting in secondary complications of infection and stiffness.

Anatomically these bones lie in narrow difficult to expose confines with minimal overlying soft tissue cover. Being in proximity to joints and linked by ligaments and capsular structures, these fractures are subjected to disruptive and destabilising forces, promoting non-unions. The bony complications are often accompanied with surrounding scarring and adhesions. These reasons prevent the success of non-vascularised bone grafts.

Use of vascularised conventional bone grafts requires the harvest of very small dimensions of bone graft with an intact and delicate nutrient artery running in continuity with the main pedicle. The high osteogenic potential of the cambium layer of periosteum is well known. Based on this, we describe the use of corticoperiosteal grafts from the medial femoral condyle (MFC) for the management of a series of eleven cases of non-unions of proximal pole fractures of scaphoid associated with avascular necrosis (AVN).

\section{MATERIALS AND METHODS}

Over 2 years, from January 2014 to January 2016, we have used vascularised MFC corticoperiosteal grafts in 11 patients. The age range of our patients has been 20-25 years-all young healthy male adults, mostly students presenting with aetiology of trauma. All patients were initially treated with conservative measures for scaphoid fracture and one had an operative fixation too. Following an initial subsidence of symptoms, the complaints recurred during attempted movements of wrist joint. Almost all presented to us after 1 year of symptoms. The reasons for delayed presentation have been variable but most put it as a vague discomfort that they had lived with and presented for treatment as it became persistent.

Radiographs revealed non-union proximal pole of scaphoid in all cases. Magnetic resonance imaging (MRI) scan was done in all cases to study the changes in spatial orientation of scaphoid with respect to the rest of the carpus. Special sequences and the use of gadolinium as contrast helped to confirm the presence of AVN of the proximal pole. It also helped to assess the requisite dimensions of bone graft and planning its fixation [Figures 1 and 2]. All patients were operated under general anaesthesia with a two team approach. The orthopaedic hand surgeon exposed the non-union site, freshened the edges of the defect, inset the graft and fixed it [Figures 3 and 4]. The plastic surgery team harvested the graft and completed the anastomosis.

\section{Method of flap harvest}

Markings were done as follows - The thigh opposite to the affected hand was used. The lower limb was abducted and laterally rotated at the hip joint keeping it flexed at the knee joint. The medial knee joint line was marked. The axis of adductor longus was drawn from pubic tubercle downwards till the knee joint line. One centimeter anterior to this line, the line of incision was marked starting from the knee joint line upwards for a distance of $10 \mathrm{~cm}$ [Figure 5]. This roughly overlies the intermuscular septum between the adductor magnus and vastus medialis muscle [Figure 6].

Upper thigh tourniquet was applied and elevated after gentle exsanguination. After skin and subcutaneous tissue were incised, the fascia overlying the vastus medialis was incised at its medial margin right below the skin incision. Here, one can feel and visualise the septum between the two muscles-vastus medialis and adductor magnus. The fascia covering vastus medialis muscle at the medial margin is attached to the intermuscular septum.

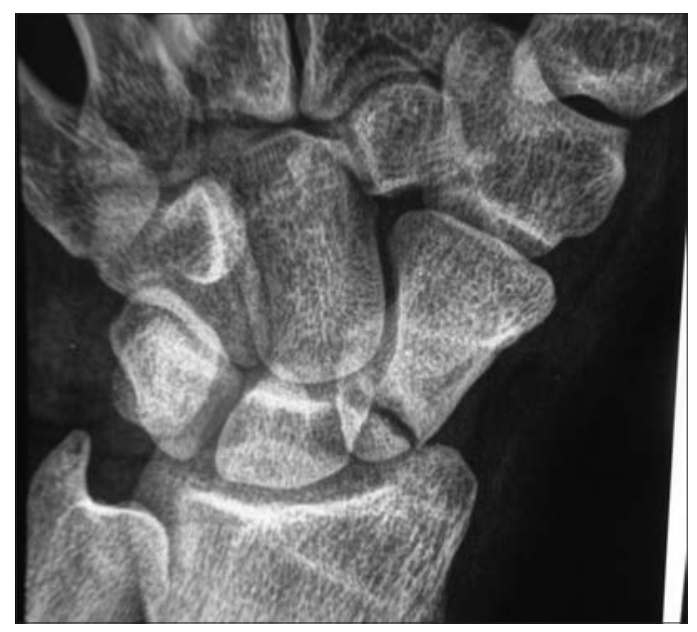

Figure 1: Plain radiograph showing non-union of scaphoid

Indian Journal of Plastic Surgery Volume 50 Issue 2 May-August 2017 


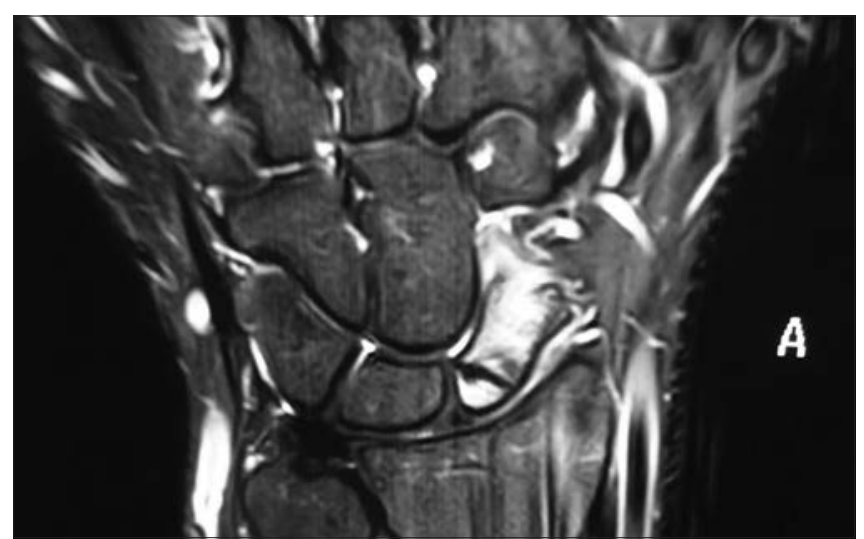

Figure 2: Magnetic resonance imaging scan showing non-union along with spatial relation of scaphoid with the rest of the carpus

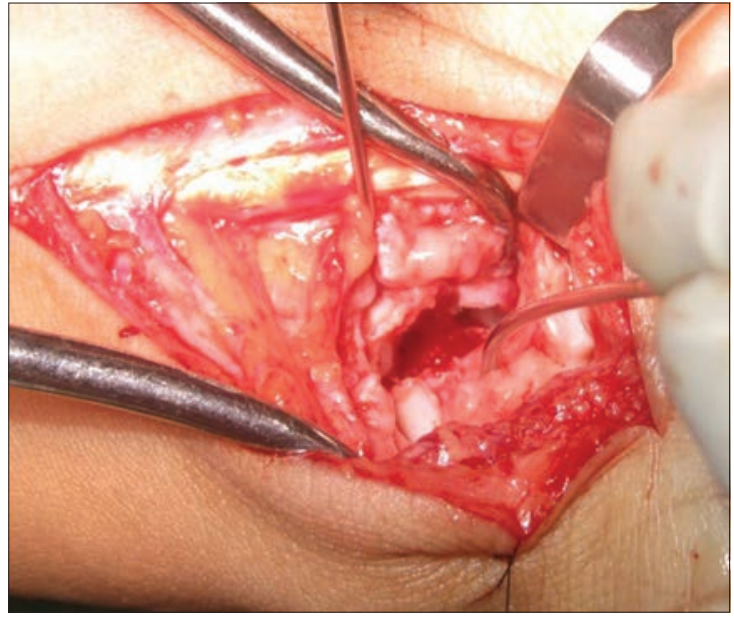

Figure 4: Ends of scaphoid freshened and gap assessed

After incising the fascia, vastus medialis is retracted anteriorly away from the septum to expose the pedicle. The pedicle-descending genicular artery (DGA) can be seen to arise from superficial femoral artery (SFA) just proximal to the adductor hiatus [Figure 7a]. This was then followed proximally to obtain a good lumen size and the pedicle was dissected off all its muscular branches. It was followed distally to the point where it entered the periosteum of the medial condyle. A rich leash of vessels can be seen flaring over an area of 5-7 cm enabling a reasonably large sized graft to be harvested if required. This also indicates the density of vascular supply of the periosteum [Figure 7b].

The DGA divides into a transverse branch about $4-5 \mathrm{~cm}$ proximal to the articular surface of the condyle and a longitudinal branch which runs down over the surface of the condyle. Just proximal to this division of DGA, is the origin of superomedial genicular artery (SMGA) from popliteal artery. This joins the DGA just at or about the division into transverse and longitudinal branches. SMGA

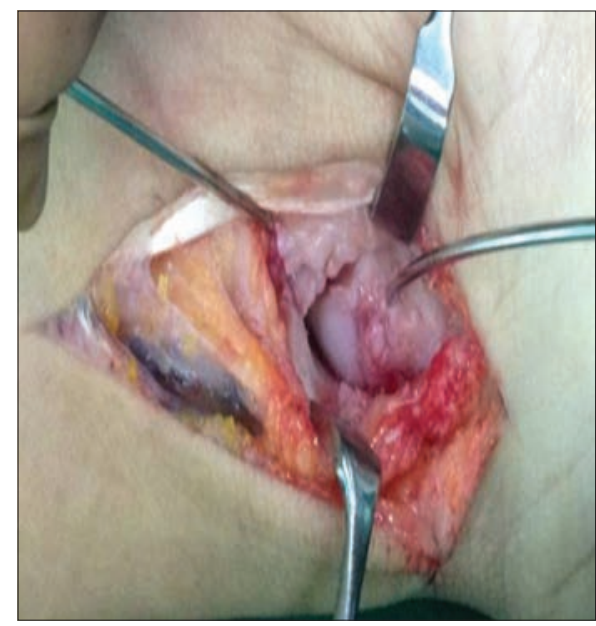

Figure 3: Volar approach to expose the non-union site

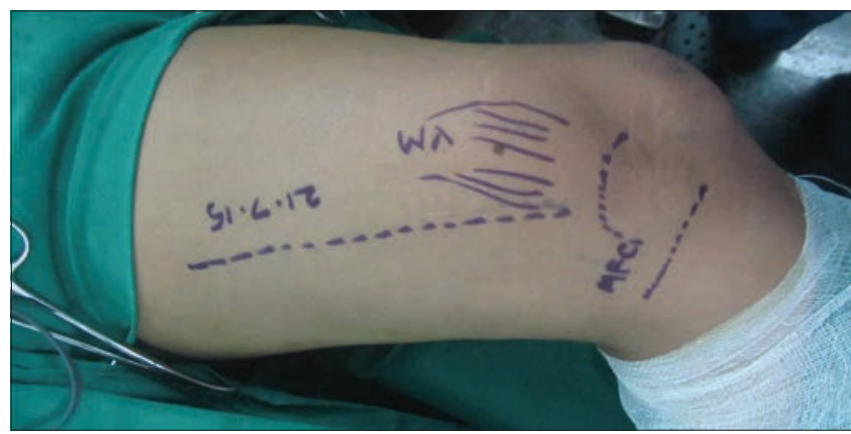

Figure 5: Markings for medial femoral condyle flap: intermuscular septum marked $1 \mathrm{~cm}$ anterior to line of adductor longus

may be the dominant supply in about $20 \%$ of patients in whom the DGA may be absent. However, when SMGA is the dominant supply, the difference in sizes of vessels at the point of entry is quite obvious. This branch is ligated, and pedicle is made free throughout the course except the distal $5-8 \mathrm{~mm}$ where it is elevated along with the periosteum [Figure 7c].

The markings of requisite bone graft were made and periosteum was elevated beyond the margins to take more of periosteum relative to the cortex. Drill holes were then made in the cortex to mark out the area of the graft. A fine osteotome was used to harvest the piece of graft. The maximum size of graft that we harvested was about $2.5 \mathrm{~cm} \times 2.5 \mathrm{~cm}$ with the average being $1.5 \mathrm{~cm} \times 2 \mathrm{~cm}$ [Figure $7 \mathrm{~d}$ ]. After the corticoperiosteal graft was completely excised, the last periosteal attachment was now released. This was at the proximal margin of the graft along which ran the distal part of the pedicle. This periosteal sleeve was lifted up with the pedicle off the bone taking care to ligate small branches that ran proximally. The distal limit of the graft is about $2 \mathrm{~cm}$ short of the joint line, and proximal limit is just 


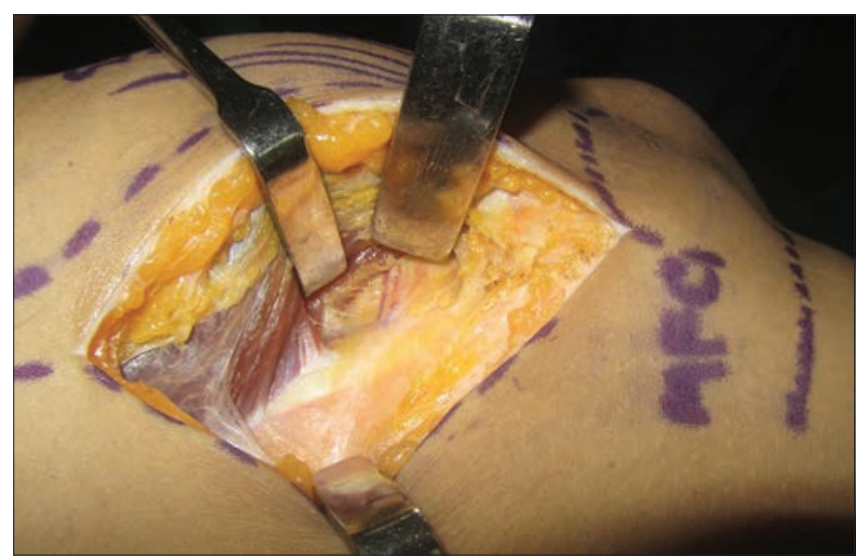

Figure 6: Incision corresponds to the septum and fibres of vastus medialis muscle retracted anteriorly to expose the periosteal supply from descending genicular artery

short of the condyle and shaft junction. Medially, it is limited by the attachments of the medial collateral ligament. In general, the condyle has a broad surface area and the graft required is quite small, so it can be safely centred on the condyle without encroaching any of its peripheral limits. Cancellous bone was then harvested from the same site. Haemostasis attained and a suction drain placed [Figure $8 \mathrm{~b}$ ]. We preferred suturing the fascia overlying vastus medialis to the septum, and then the skin was closed in layers. With experience, the size of our skin incision was reduced to about $7-8 \mathrm{~cm}$ as pedicle length required for anastomosis was just about 4-5 cm [Figure 8a]. We preferred immobilising the thigh with a long knee brace for 4-6 weeks permitting the patient to bear weight as per the patient's comfort. Knee bending exercises were started at the time of suture removal.

The approach to scaphoid can be dorsal or volar depending on the location of the fracture and the donor vessel selected. We have used the latter in all cases, and the radial artery was exposed through the same incision [Figure $8 \mathrm{c}$ ]. The graft was trimmed and fit into the defect, with cancellous bone being placed all around and immobilised with 1-1.2 $\mathrm{mm}$ K-wires or cannulated headless screws. In case of dorsal intercalated segment instability (DISI) deformities, where the scaphoid was flexed, a wire fixing the scaphoid to the capitate with the scaphoid held in extension was added. End to end venous anastomoses was done with the radial venae commitantes or cephalic vein followed by end-side arterial anastomosis with radial artery. Skin closure was done in a single layer and the forearm and hand were immobilised in a dorsal slab for about 2 weeks.

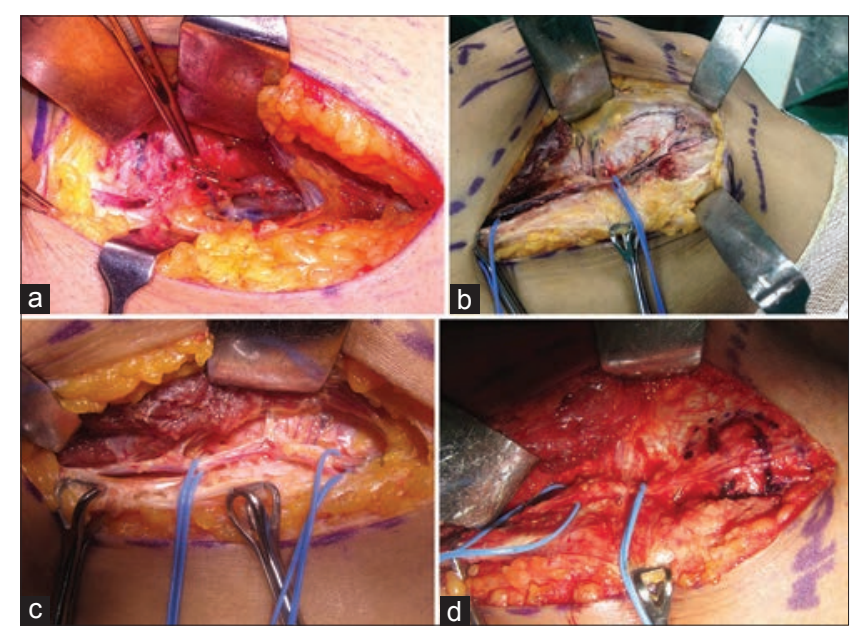

Figure 7: Vascular pedicle anatomy and dissection (a) Origin of descending genicular artery descending genicular artery (held with the forceps) from superficial femoral artery at the adductor hiatus; also seen is a cutaneous perforator, (b) Osteoarticular branch of descending genicular artery divides into a transverse and a longitudinal branch forming the filigree pattern of periosteal vascular leash, (c) Proximal dissection of the vascular pedicle with inclusion of longitudinal branch for harvesting of non-articular cortico-periosteal graft, (d) Tourniquet released to assess perfusion of the medial femoral condyle and area of bone graft marked

We have then followed up all patients with serial radiographs starting from 2 weeks post-operatively and repeating every 2 weeks. Evidence of union was seen around $10-16$ weeks on serial radiographs.

\section{RESULTS}

All patients did well as evidenced by radiological union. Time of union was an average 12 weeks as observed on serial radiographs which was satisfactory. We had neither flap loss nor any non-union There were no significant donor site complications/morbidities in any of the patients apart from scar hypertrophy and mild paresthesia over the medial aspect of the knee. Physiotherapy for the wrist was started at 8 weeks. The pain was relieved in all patients. The pre-operative range of motion in all patients was preserved, and an improved range was noted in three patients [Table 1]. The maximum range of motion was achieved in all patients by 12 weeks. Dorsiflexion of the wrist was in the range of $60^{\circ}-70^{\circ}$ in all patients; except one patient who had dorsiflexion of about $40^{\circ}$. Volar flexion of the wrist was in the range of $70^{\circ}-80^{\circ}$ in all [Figure 9].

\section{DISCUSSION}

The anatomical layout of small bones is superficial, and their position is amidst adjacent joints such that the function of one inevitably affects the function of 
Table 1: Master chart

\begin{tabular}{|c|c|c|c|c|c|c|c|c|}
\hline $\begin{array}{l}\text { Non-union } \\
\text { duration } \\
\text { (years) }\end{array}$ & $\begin{array}{c}\text { Pre- } \\
\text { operative } \\
\text { AVN } \\
\text { (yes/no) }\end{array}$ & $\begin{array}{l}\text { Previous } \\
\text { surgery }\end{array}$ & $\begin{array}{l}\text { Pedicle } \\
\text { length } \\
\text { harvested } \\
\text { (cm) }\end{array}$ & $\begin{array}{l}\text { Recipient } \\
\text { vessels (end- } \\
\text { end/end-side) }\end{array}$ & Fixation & $\begin{array}{l}\text { Re-exploration/ } \\
\text { failure }\end{array}$ & $\begin{array}{l}\text { Donor site morbidity } \\
\text { (pain, reduced range } \\
\text { of movements, } \\
\text { abnormal scar, } \\
\text { paresthesia) }\end{array}$ & $\begin{array}{l}\text { Recipient site } \\
\text { morbidity (pain, } \\
\text { reduced range } \\
\text { of movements, } \\
\text { abnormal scar) }\end{array}$ \\
\hline 1 & Yes & K-wire & 7 & $\begin{array}{l}\text { Superficial radial } \\
\text { artery end-end }\end{array}$ & K-wire & None & Nil & Stretched scar \\
\hline 9 & Yes & $\begin{array}{l}\text { Non-d scularised } \\
\text { bone graft }\end{array}$ & 8 & $\begin{array}{l}\text { Radial artery } \\
\text { end-side }\end{array}$ & K-wire & None & Nil & Nil \\
\hline 2 & Yes & K-wire & 9 & $\begin{array}{l}\text { Radial artery } \\
\text { end-side }\end{array}$ & K-wires & None & Hypertrophic scar & Nil \\
\hline 1 & Yes & None & 8 & $\begin{array}{l}\text { Radial artery } \\
\text { end-side }\end{array}$ & K-wires & None & Nil & $\begin{array}{l}\text { Hypertrophic } \\
\text { scar }\end{array}$ \\
\hline 2 & Yes & $\begin{array}{l}\text { Vascularised } \\
\text { distal radius graft }\end{array}$ & 10 & $\begin{array}{l}\text { Superficial radial } \\
\text { artery end-end }\end{array}$ & K-wires & None & Stretched scar & Nil \\
\hline 1 & Yes & None & 9 & $\begin{array}{l}\text { Superficial radial } \\
\text { artery end-end }\end{array}$ & K-wires & None & Nil & Nil \\
\hline 1.5 & No & None & 8 & $\begin{array}{l}\text { Radial artery } \\
\text { end-side }\end{array}$ & $\begin{array}{l}\text { Cannulated } \\
\text { screw }\end{array}$ & None & Hypertrophic scar & $\begin{array}{l}\text { Scar } \\
\text { hypertrophy }\end{array}$ \\
\hline 2 & No & $\begin{array}{l}\text { Non- } \$ \text { scularised } \\
\text { bone graft }\end{array}$ & 7 & $\begin{array}{l}\text { Radial artery } \\
\text { end-side }\end{array}$ & K-wire & None & Nil & Nil \\
\hline 1 & Yes & Screw & 8 & $\begin{array}{l}\text { Superficial radial } \\
\text { artery end-end }\end{array}$ & K-wire & None & Nil & Nil \\
\hline 3 & Yes & Screw & 8.5 & $\begin{array}{l}\text { Superficial radial } \\
\text { artery end-end }\end{array}$ & K-wire & None & Nil & Nil \\
\hline 1.5 & No & None & 9 & $\begin{array}{l}\text { Radial artery } \\
\text { end-side }\end{array}$ & $\begin{array}{l}\text { Cannulated } \\
\text { screw }\end{array}$ & None & Nil & Scar hypertrophy \\
\hline
\end{tabular}

AVN: Aa scular necrosis

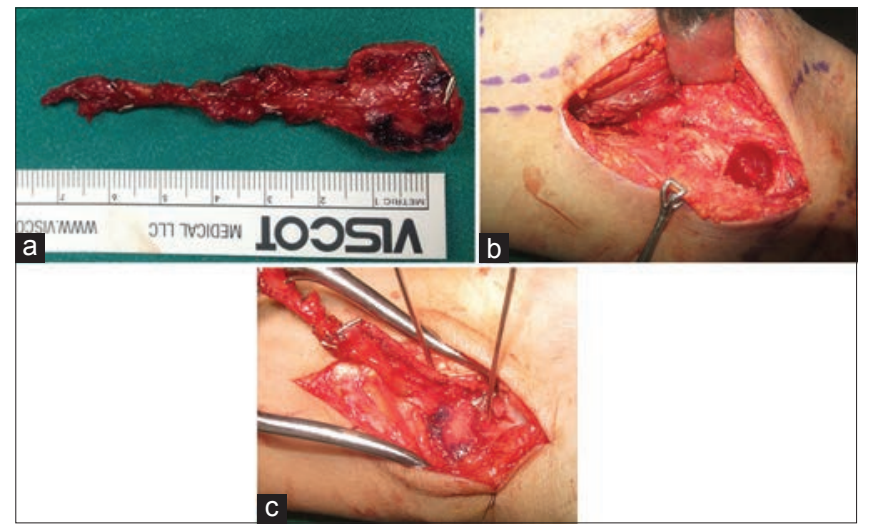

Figure 8: Flap inset and anastomosis (a) Pedicle length obtained is about $7-8 \mathrm{~cm}$, (b) Bony defect after graft harvest and cancellous bone can be hare sted from the same sight, (c) Volar approach to inset the graft into the defect and and end - side anastomosis with the radial artery

the other. Non-union of these small bones can lead to secondary complications in neighbouring structures with more scarring affecting the blood supply to the fractured ends. Further, the presence of factors such as infection, open fracture, attempts at previous internal fixation and associated soft tissue defect, increase the risk and extent of local bone devascularisation. Thus, in such cases, primary bone grafting is advocated by del Piñal et al., in view of these fractures going in for a recalcitrant non-union. ${ }^{[1]}$ In a meta-analysis of the literature by Merrell et al., vascularised bone grafting of Indian Journal of Plastic Surgery Volume 50 Issue 2 May-August 2017

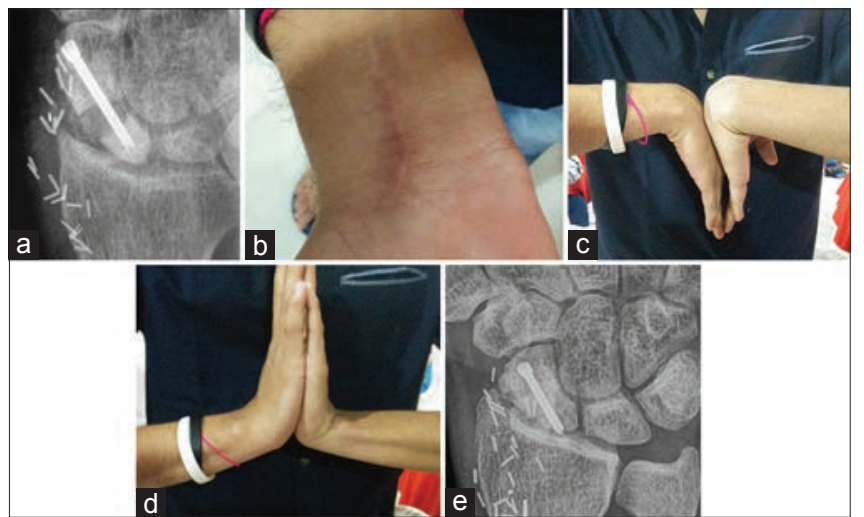

Figure 9: (a) Radiograph assessing the fixation with $\mathrm{K}$ wires or cannulated screws, (b) satisfactory scar over the forearm, (c and d) range of motion achieved, (e) union at the end of 8 weeks

scaphoid non-unions with osteonecrosis was found to be associated with a union rate of $88 \%$ as compared with $47 \%$ in association with conventional (non-vascularised) grafting. ${ }^{[2]}$

Natural history studies of symptomatic scaphoid non-unions have shown a uniform progression of degenerative carpal arthritis, the severity of arthritis being proportional to the duration of the non-union. A symptomatic scaphoid non-union with displacement and instability will result in degenerative arthritis, and even asymptomatic undisplaced non-unions can go in 
for degenerative changes. Vascularised bone grafts have been advocated for the treatment of the former. ${ }^{[3]}$

The DISI deformity-dorsal intercalated scaphoid instability is defined as revised carpal height ratio of $\leq 1.52$ (normal, $1.57 \pm 0.05$ ) or a radiolunate angle of $\geq 15^{\circ}$ (normal, $\leq 10^{\circ}$ ). Foreshortening or humpback deformity as described by Jones et al. from Mayo clinic is defined as a lateral intrascaphoid angle of $\geq 45^{\circ}$ (normal, $\leq 35^{\circ}$ ). Proximal pole avascularity is evidenced by the pre-operative radiographic finding of increased bone density, occasionally associated with loss of trabecular structure, the collapse of the subchondral bone and formation of bone cysts. MRI with absent T1 and T2 signals and diminished uptake of contrast with gadolinium enhancement. The final confirmation of avascularity occurs during surgery by observation of white, sclerotic bone with absent punctate bleeding on tourniquet release. ${ }^{[4]}$

Treatment guidelines have been proposed by Jones et al. with regards to DISI deformity and AVN-if the scaphoid has evidence of AVN, a vascularised graft should be used given the significantly improved rate of union with these grafts than with non-vascularised grafts. If scaphoid geometry and carpal alignment are maintained as evidenced by normal carpal indices, an inlay graft such as the 1, 2 intercompartmental supraretinacular artery graft is used. However, for scaphoid non-unions associated with both AVN and collapse, a vascularised interposition wedge graft is selected. ${ }^{[5]}$

Although vascularised fibula/iliac crest bone grafts have been used for treatment of long bone non-unions as shown by Taylor et al., ${ }^{[6]}$ using the same for small bone non-unions is technically not possible because it is not always possible to accurately locate the nutrient artery and harvest a small segment with its pedicle. Further improvements were done by Harpf et al. ${ }^{[7]}$ who used iliac crest vascularised blocks and by del Piñal et al ${ }^{[8]}$ who used vascularised toe phalanges, but none served the purpose and seemed too big due to the anatomical limitation of space and the small chunks of bone could not be made to conform to the small gaps. That apart, an overhanging graft could restrict movements of adjacent joints and tendons.

In 2001, Harpf et al. reported on sixty scaphoid non-unions ( 26 with an avascular proximal pole) treated with free vascularised iliac crest bone grafts. The authors found an overall union rate of $91.7 \%$. The union rate for the non-unions associated with an avascular proximal pole was $90 \%$; however, it should be noted that none of these wrists had a carpal collapse or humpback deformity and all grafts were used as an inlay graft. Donor site morbidity was high, with a $55 \%$ prevalence of hyperostosis of the iliac crest, an $8.3 \%$ prevalence of deformity of the iliac crest, and a $31.7 \%$ prevalence of nerve hypoesthesia. ${ }^{.7]}$

A retrospective review of patients with humpback deformity and AVN from the Mayo Clinic and the Landeskrankenhaus Klagenfurt (Klagenfurt, Austria) was conducted comparing two techniques-distal radial graft based on a 1,2 intercompartmental supraretinacular artery pedicle with MFC vascularised corticoperiosteal graft on 22 non-unions. Four of 10 non-unions treated with the 1, 2 ICSRA pedicled radius graft healed at a mean of 19 weeks, and all 12 non-unions treated with the MFC graft healed at a mean of 13 weeks. This rate of union was significantly higher $(P=00.005)$ and the median time to healing significantly shorter $(P<0.001)$ for the MFC grafts. ${ }^{[9]}$ Zaidemberg et al. and Sheetz et al. described the 1, 2 intercompartmental supraretinacular artery flap from the distal radius. ${ }^{[10,11]}$ The limitations of this bone flap include poor quality of distal radius bone, variable vascularity, and difficulty in incorporating it into rigid fixation. Furthermore, prior surgery on the distal radius or through the soft tissue in the area may preclude its availability. They further concluded that the vascularised pedicled distal radial bone graft was not sufficient to maintain carpal alignment and was associated with an unacceptably high failure rate when used to treat non-unions with both osteonecrosis and carpal collapse..$^{[9]}$ The MFC graft has structural integrity and a robust blood supply while causing minimal donor site morbidity. ${ }^{[12]}$

The osteogenic potential of periosteum was first described by Gysel and Henri-Louis Duhamel du Monceau in $1700^{[13]}$ while the importance of cambium layer as the source of osteoblasts was described much later. ${ }^{[14]}$ Several donor sites of periosteal grafts were described by Penteado et al. ${ }^{[15]}$ including the humerus, radius, ulna, tibia and femur.

Studies by Sakai had shown the importance of cambium layer and to safeguard this layer he advocated harvesting of corticoperiosteal grafts. ${ }^{[16]}$ This helps in preserving the osteogenic potential of osteoblasts lying in the cambium (innermost layer of periosteum) along with 
inclusion of highly vascular outer periosteal layers. The superiority of corticoperiosteal grafts over either cortical alone or periosteal alone is based on the high osteogenic, osteoinductive and osteoblastic capacity of periosteum as a whole. Grafts from the MFC were initially described by Hertel and Masquelet as pedicled periosteal and osteoperiosteal grafts based on branches of the DGA. ${ }^{[17]}$

Free corticoperiosteal graft from the MFC was first described by Doi and Sakai in 1994. ${ }^{[18]}$ This graft is supplied by DGA $(80 \%-87 \%)$ from the SFA given off at the adductor hiatus or from the SMGA (13\%-20\%) from popliteal artery. ${ }^{[19]}$ MFC corticoperiosteal vascularised graft has a distinct and well-defined anatomy. Surface anatomical marking of the adductor longus and medial joint line are made; $1 \mathrm{~cm}$ anterior to adductor longus lies the intermuscular septum and medial attachment of vastus medialis to the septum. The SFA and its branches can be well visualised beneath the medial border of vastus medialis at the base of the septum. Proximal to the hiatus is given off the medial metaphyseal periosteal artery, (MMPA) and then DGA. ${ }^{[20]}$ DGA branches from the SFA $14.2 \mathrm{~cm} \pm 2.4 \mathrm{~cm}$ proximal to the knee joint line. The length of the vascular pedicle of DGA to attachment onto the periosteum was $7.7 \mathrm{~cm} \pm 2.2 \mathrm{~cm}$. With SMGA, 4-5 cm of pedicle length is obtained. The MMPA demonstrated the proximal-most perfusion of the DGA at a level of $13.7 \mathrm{~cm} \pm 1.3 \mathrm{~cm}$ proximal to the joint line. The inclusion of MMPA is essential when a large segment of corticoperiosteal flap needs to be harvested. The DGA provided perfusion of $29.2 \% \pm 2.3 \%$ of the total length of the medial femur ${ }^{[21]}$ that is one-third of total femur length. DGA then gives off the saphenous artery, muscular branches and osteoarticular branch. The last further divides into a transverse and a longitudinal branch. The transverse branch goes all along till the trochlea of medial condyle which is a suitable site to harvest osteocartilaginous vascularised grafts to reconstruct articular bony defects [Figure 10].

The saphenous artery travels in the subcutaneous tissue and also there are cutaneous perforators. Thus an adipocutaneous flap can be harvested chimerically with bone flap based on either of them [Figure 11]. The saphenous nerve is an important guide to the saphenous artery and when traced distally makes it easy to identify the perforators antegrade. The cutaneous perforators can be identified by handheld Doppler and commonly found near the femoral condyle that is a distal portion of

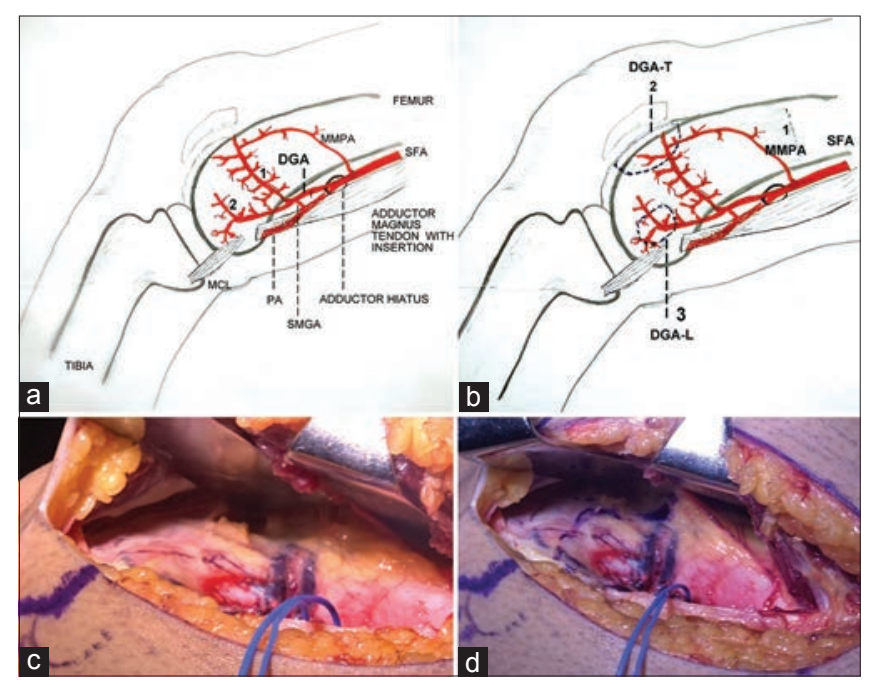

Figure 10: (a) Origins of descending genicular artery and medial metaphyseal pereiosteal artery (MMPA) from superficial femoral artery and superomedial genicular artery from popliteal artery. Division of osteoarticular branch of descending genicular artery into transe rse (1) and longitudinal branches (2), (b) \& scular supply for corticoperiosteal \& scularised graft- (1) large grafts $(13 \mathrm{~cm} \times 8 \mathrm{~cm})$ based on medial metaphyseal pereiosteal artery (MMPA) and descending genicular artery a scular supply for Osteo-articular/osteochondral vascularised graft: (2) transverse branch of osteoarticular branch of descending genicular artery (3) small grafts based on descending genicular artery, (c) The continuation of transe rse branch of descending genicular artery towards the articular surface- trochlea of medial femoral condyle, (d) marking of osteoarticular graft

the incision. This makes it easy to harvest after the DGA pedicle is dissected. Perforator length of cutaneous flap obtained is also satisfactory about $4-6 \mathrm{~cm}$, which makes the positioning of the skin paddle easy and independent of bone flap. This skin flap has several uses such as external marker of vascularity of bone flap after anastomosis, skin for composite reconstructions of interphalangeal joints and phalangeal non-unions primarily or for secondary skin resurfacing treated earlier with skin grafts, skin resurfacing after small bone non-unions grafting where the skin though adequate may seem tight after graft placement.

The distinct appearance of MFC is its filigree pattern of rich vascular supply called area cribrosa vasorum condyloidae medialis and lateralis by Rogers and Gladstone in 1950. ${ }^{[22]}$ This dense vascular periosteal supply of MFC along with the high osteogenic potential of cambium indeed makes this site an ideal choice to tackle difficult bony non-unions irrespective of site and size. Thus, the MFC is a rich donor site of two types of vascularised bone grafts:

1. Corticoperiosteal vascularised graft

a. Small grafts based on DGA

b. Large grafts $(13 \mathrm{~cm} \times 8 \mathrm{~cm})$ based on MMPA and DGA

2. Osteoarticular/osteochondral vascularised graft 


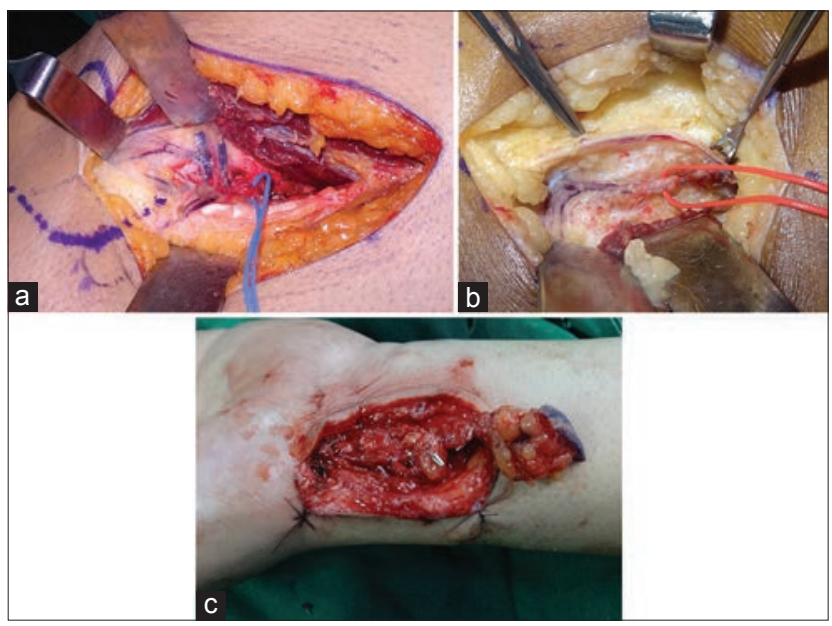

Figure 11: Cutaneous supply o® $r$ medial femoral condyle (a) cutaneous perforator from DGA seen at division of osteoarticular branch into transverse and longitudinal branches, (b) saphenous artery branch from DGA accompanied with the saphenous nerve is another source of supply to skin over medial femoral condyle, (c) chimeric flap including corticoperiosteal graft and cutaneous flap with freedom of placement of cutaneous flap

a. Based on a transverse branch of osteoarticular branch of DGA.

Indications for:

1. Small corticoperiosteal grafts: Small bone non-unions of hand and foot, large bone small non-unions-clavicle, upper and lower limb

2. Large corticoperiosteal vascularised grafts: Calvarial grafting

3. Osteoarticular vascularised grafts: Articular surface resurfacing of interphalangeal joints and metacarpophalangeal joints.

The distinct advantages of this site are:

1. Superficial location of condyle providing a broad area of graft that can be harvested without affecting the articulation or strength of femur shaft. An average $1.5 \mathrm{~cm} \times 2 \mathrm{~cm}$ is more than sufficient but grafts as big as $13 \mathrm{~cm} \times 8 \mathrm{~cm}$ have been used from the MFC for cranioplasties ${ }^{[18]}$

2. Pedicle location is well described anatomically and harvesting the pedicle requires no intramuscular dissection nor does it cause any donor site morbidity. Not much length is required and the diameter of DGA at the adductor hiatus is about $1.5-2.5 \mathrm{~mm}$

3. Anatomic variation of blood supply of graft by SMGA which branches from the popliteal artery occurs in about $20 \%{ }^{[19]}$ The difficulty with this vessel is the smaller vessel diameter and pedicle length being about 4-5 cm. However, the length of pedicle required at the recipient site is also not much. Hence, this suffices
4. The MFC has a dense periosteal leash of vessels, described as a 'filigree pattern', which stands out distinctly during dissection. The course is the direct continuation of the pedicle distally into the supra-articular condylar area. Thus, highly vascularised tissue can be harvested without any danger of leaving the source artery behind or damaging the pedicle. The flap dissection is relatively straight forward, once the pedicle is identified beneath the medial attachment of fascia of vastus medialis to intermuscular septum between vastus and adductor magnus. Harvest time can be as short as $30-40$ min with the pedicle being identified within first 5 min of incision

5. Thin corticoperiosteal graft can be easily tailored to fit into the defect. It can be used to drape around tubular bones such as phalanges, radius, ulna, and clavicle to improve union [Figures 12 and 13]

6. Cancellous bone can be harvested from the same site

7. A chimeric flap can be harvested from the same site using one of the skin perforators from DGA used for monitoring or in the case of composite defects of the digits $^{[20]}$

8. Donor site scar is quite concealed and well accepted. No donor site morbidities have been reported in any of the studies till date except for transient numbness over lower medial thigh in one. On long-term follow-up of the donor site, no incidences of fracture have been noted ${ }^{[23]}$

9. It lies away from recipient site allowing a two team approach.

Surgical tips in MFC corticoperiosteal vascularised graft harvesting:

1. Identification of intermuscular septum

2. Tracing the pedicle retrograde as it is easily identifiable over the MFC due to its classical filigree pattern. Thus, the condyle is exposed in the distal part of the incision, the vastus is then lifted off anteriorly to find the periosteal leash over the condyle leading proximally to DGA

3. Articular surface harvested by tracing the transverse branch of an osteoarticular branch of DGA

4. SMGA joins the DGA just at or about the division into transverse and longitudinal branches; this needs to be preserved till proximal length and diameter of DGA are found to be satisfactory. This SMGA comes as a posterior branch

5. A high thigh tourniquet makes the field bloodless.

The Mayo Clinic studies ${ }^{[4]}$ have also recommended the following conditions when MFC is to be avoided: 


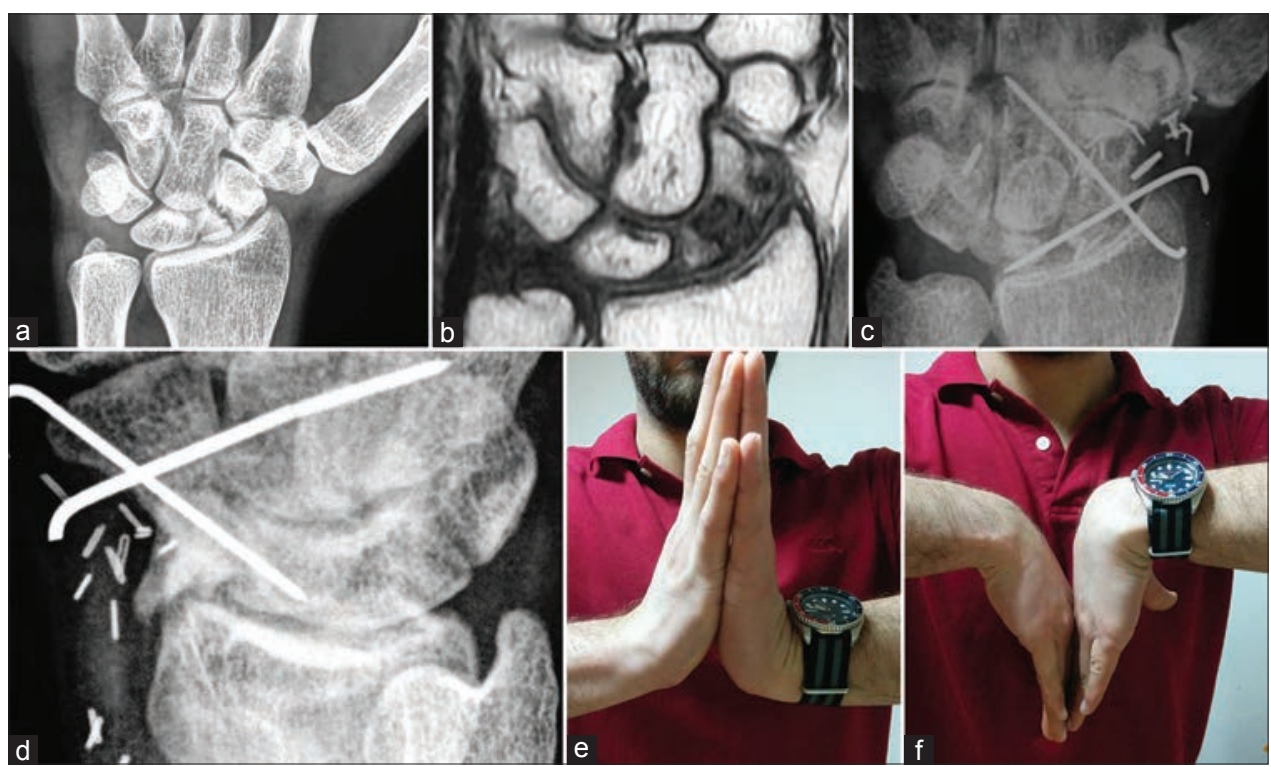

Figure 12: Case 1 (a) Proximal pole scaphoid non-union, (b) Magnetic resonance imaging showing avascular necrosis, (c) Medial femoral condyle vascularised graft placed and stabilised with cross $\mathrm{K}$ wires, (d) Radiological appearance at 1 month, (e): Range of movements at the end of 6 months, (f): Range of movements at the end of 6 months

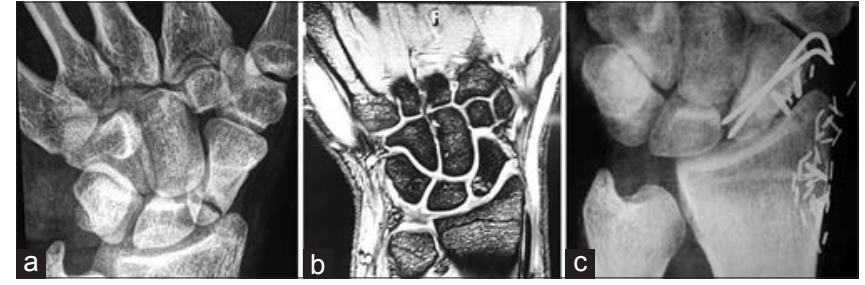

Figure 13: Case 2 (a) Proximal pole scaphoid non-union, (b) A magnetic resonance imaging showing avascular necrosis, (c) X-ray showing union

1. Radiographic or intraoperative evidence of radioscaphoid arthritis. Salvage procedures, such as wrist denervation, scaphoid excision and four corner fusion, proximal row corpectomy or complete wrist fusion can be used

2. Ununited scaphoid fractures with normal geometry and proximal pole avascularity: An inlay pedicled vascularised graft

3. Scaphoids with foreshortening but without evidence of osteonecrosis: Non-vascularised wedge grafts and internal fixation.

\section{CONCLUSION}

Indeed, the medial femoral corticoperiosteal graft seems to satisfy the need for a small, thin, pliable, highly vascular tissue of optimal osteogenic potential to conform into non-unions of small bones restoring them to the timely union and improved function. The success rates of these grafts are seen at present, to better those of vascularised distal radius grafts in patients with scaphoid waist Indian Journal of Plastic Surgery Volume 50 Issue 2 May-August 2017 non-union associated with carpal collapse (humpback deformity) and osteonecrosis of the proximal pole.

\section{Financial support and sponsorship \\ Nil.}

\section{Conflicts of interest}

There are no conflicts of interest.

\section{REFERENCES}

1. González del Pino J, Bartolomé del Valle E, Graña GL, Villanova JF. Free vascularized fibular grafts have a high union rate in atrophic nonunions. Clin Orthop Relat Res 2004;419:38-45.

2. Merrell GA, Wolfe SW, Slade JF $3^{\text {rd }}$. Treatment of scaphoid nonunions: Quantitatie meta-analysis of the literature. J Hand Surg Am 2002;27:685-91.

3. Mack GR, Bosse MJ, Gelberman RH, Yu E. The natural history of scaphoid non-union. J Bone Joint Surg Am 1984;66:504-9.

4. Jones DB Jr., Bürger H, Bishop AT, Shin AY. Treatment of scaphoid waist nonunions with an avascular proximal pole and carpal collapse. Surgical technique. J Bone Joint Surg Am 2009;91 Suppl 2:169-83.

5. Jones DB Jr., Moran SL, Bishop AT, Shin AY. Free-vascularized medial femoral condyle bone transfer in the treatment of scaphoid nonunions. Plast Reconstr Surg 2010;125:1176-84.

6. Taylor GI, Miller GD, Ham FJ. The free vascularized bone graft. A clinical extension of microvascular techniques. Plast Reconstr Surg 1975;55:533-44.

7. Harpf C, Gabl M, Reinhart C, Schoeller T, Bodner G, Pechlaner S, et al. Small free vascularized iliac crest bone grafts in reconstruction of the scaphoid bone: A retrospectie study in 60 cases. Plast Reconstr Surg 2001;108:664-74.

8. del Piñal F, García-Bernal FJ, Delgado J, Sanmartín M, Regalado J, Cagigal L. Vascularized bone blocks from the toe phalanx to solve complex intercalated defects in the fingers. J Hand Surg Am 2006;31:1075-82. 
9. Jones DB Jr., Bürger H, Bishop AT, Shin AY. Treatment of scaphoid waist nonunions with an avascular proximal pole and carpal collapse. A comparison of two vascularized bone grafts. J Bone Joint Surg Am 2008;90:2616-25.

10. Sheetz KK, Bishop AT, Berger RA. The arterial blood supply of the distal radius and ulna and its potential use in vascularized pedicled bone grafts. J Hand Surg Am 1995;20:902-14.

11. Zaidemberg $C$, Siebert JW, Angrigiani $C$. A new vascularized bone graft for scaphoid nonunion. J Hand Surg Am 1991;16:474-8.

12. Friedrich JB, Pederson WC, Bishop AT, Galaviz P, Chang J. New workhorse flaps in hand reconstruction. Hand (NY) 2012;7:45-54.

13. Gysel C. Henri-Louis Duhamel du Monceau (1700-1782-1982), growth and osteogenic function of the periosteum. Orthod $\mathrm{Fr}$ 1983;54:605-21.

14. Ueno $\mathrm{T}$, Kagawa $\mathrm{T}$, Mizukawa N, Nakamura H, Sugahara $\mathrm{T}$, Yamamoto T. Cellular origin of endochondral ossification from grafted periosteum. Anat Rec 2001;264:348-57.

15. Penteado CV, MasqueletAC, Romana MC, Cherv el JP. Periosteal flaps: Anatomical bases of sites of elevation. Surg Radiol Anat 1990;12:3-7.

16. Sakai K, Doi K, Kawai S. Free vascularized thin corticoperiosteal graft. Plast Reconstr Surg 1991;87:290-8.
17. Hertel R, Masquelet AC. The reverse flow medial knee osteoperiosteal flap for skeletal reconstruction of the leg. Description and anatomical basis. Surg Radiol Anat 1989;11:257-62.

18. Doi K, Sakai K. Vascularized periosteal bone graft from the supracondylar region of the femur. Microsurgery 1994;15:305-15.

19. Lapierre F, Masquelet A, Aesch B, Romana C, Goga D. Cranioplasties using free femoral osteo-periostal flaps. Chirurgie 1991;117:293-6.

20. Martin D, Bitonti-Grillo C, De Biscop J, Schott H, Mondie JM, Baudet $\mathrm{J}$, et al. Mandibular reconstruction using a free vascularised osteocutaneous flap from the internal condyle of the femur. Br J Plast Surg 1991;44:397-402.

21. Matthew L, lorio, Masden D, Higgins JP. Periosteal angiosome of the descending geniculate artery. Plastic surgery 2011, abstract supplement. Suppl Plast Reconstr Surg 2011;128:32-3.

22. Rogers WM, Gladstone $H$. Vascular foramina and arterial supply of the distal end of the femur. J Bone Joint Surg Am 1950;32:867-74.

23. Rao SS, Sexton CC, Higgins JP. Medial femoral condyle flap donor-site morbidity: A radiographic assessment. Plast Reconstr Surg 2013;131:357e-62e. 